\title{
Plasma homocysteine concentration is decreased by dietary intervention*
}

\author{
Marja-Leena Silaste ${ }^{1} \dagger$, Maire Rantala ${ }^{1}$, Georg Alfthan ${ }^{2}$, Antti Aro $^{2}$ and Y. Antero Kesäniemi ${ }^{1}$ \\ ${ }^{1}$ Department of Internal Medicine and Biocenter Oulu, University of Oulu, Kajaanintie 50, P.O. Box 5000, FIN-90014 Oulu, \\ Finland \\ ${ }^{2}$ National Public Health Institute (KTL), Mannerheimintie 166, FIN-00300, Helsinki, Finland
}

(Received 19 November 2001 - Revised 17 September 2002 - Accepted 30 September 2002)

\begin{abstract}
High plasma total homocysteine (tHcy) concentration is reported to be a risk factor for vascular diseases. We investigated the extent to which serum folate and plasma tHcy respond to a high intake of natural folate from food. Thirty-seven healthy females volunteered to participate in a crossover dietary intervention. The study included a baseline period and two 5-week diet periods (low- and high-folate diets) with a 3-week washout in between. The low-folate diet contained one serving of both vegetables and fruit/d, while during the high-folate diet the subjects ate at least seven servings of vegetables, berries, and citrus fruit/d. Serum and erythrocyte (RBC) folate, serum vitamin $\mathrm{B}_{12}$, and plasma tHcy concentrations were measured at the baseline and at the end of each diet period. The mean concentrations of serum and RBC folate were 11.0 (SD 3.0) nmol/l and 412 (SD 120) nmol/l at the end of the low-folate diet and 78 (95\% CI $62,94) \%$ and $14(95 \%$ CI 8,20$) \%$ higher in response to the high-folate diet $(P<0.001)$. The serum concentration of vitamin $\mathrm{B}_{12}$ remained unchanged during the intervention. The mean plasma tHcy concentration was $8.0 \mu \mathrm{mol} / \mathrm{l}$ at the end of the low-folate diet and decreased by $13(95 \%$ CI 9,18$) \%$ in response to the high-folate diet $(P<0.001)$. In conclusion, a diet high in fresh berries, citrus fruit, and vegetables effectively increases serum and RBC folate and decreases plasma homocysteine.
\end{abstract}

Diet: Folate: Homocysteine

Several studies have established a connection between a low folate status and an increased risk for neural tube defects. To prevent birth defects, $400 \mu \mathrm{g}$ dietary folic acid/d has been recommended to all women of reproductive age in the USA (Recommendations for the use of folic acid to reduce the number of cases of spina bifida and other neural tube defects, Centers for Disease Control, 1992). Folate also has an important role in homocysteine metabolism. An elevated plasma homocysteine concentration has been reported to be a risk factor for vascular diseases (Hankey \& Eikelboom, 1999; Nygård et al. 1999), and a plasma homocysteine concentration below $10 \mu \mathrm{mol} / \mathrm{l}$ has been suggested to prevent CHD (Omenn et al. 1998).

Plasma total homocysteine (tHcy) concentration is regulated by several factors. Among the nutritional factors, deficiencies of the vitamins $\mathrm{B}_{6}, \mathrm{~B}_{12}$, and folate are associated with elevated plasma tHcy concentrations (McCully, 1996). Moreover, supplementation with folic acid alone (Brouwer et al. 1999a; Jacques et al. 1999) and in combination with the vitamins $\mathrm{B}_{6}$ and $\mathrm{B}_{12}$ (Brönstrup et al. 1998) reduces the plasma tHcy concentration. Folic acid supplementation is cheap, easy and safe (Campbell, 1996). In contrast to taking supplemental vitamins, increasing the dietary intake of natural folate requires a sustained change in dietary patterns. Consequently, increasing the dietary intake of natural folate is commonly thought to be difficult, or even impossible, and most interest has hence been focused on folic acid supplementation. There are only a few studies showing that a high dietary intake of natural folate from vegetables and fruit decreases plasma tHcy (Brouwer et al. 1999b; Appel et al. 2000; Riddell et al. 2000). The settings of these studies were designed to compare the effects of dietary folate and supplemented folic acid (Brouwer et al. 1999b; Riddell et al. 2000) or different diets (Appel et al. 2000) on the plasma tHcy concentration. The present study was designed to determine the extent to which serum folate and plasma tHcy respond to a high intake of foods naturally rich in folate. We performed a randomised, well-controlled dietary intervention with two 5-week dietary phases: a diet period with a relatively low folate intake (about $220 \mu \mathrm{g} / \mathrm{d}$ ) and a diet period with a high folate

\footnotetext{
Abbreviations: RBC, erythrocyte; tHcy, total homocysteine.

*Presented in part in the 72nd Scientific Sessions, Atlanta, GA, 7-10 November 1999: Tormala M-L et al. (1999) Circulation 100, 1-25.

$\dagger$ Corresponding author: Dr Marja-Leena Silaste, fax +3588315 5348, email Marja-Leena.Silaste@oulu.fi
} 
intake (about $600 \mu \mathrm{g} / \mathrm{d}$ ). Compared with the previous diet interventions, the unique feature of the present study was a crossover design, in which each individual served as her own control.

\section{Methods \\ Subjects}

The study subjects were healthy female volunteers working at the University Hospital of Oulu. Screening clinical chemistry tests, medical examinations, and interviews by a nutritionist and a doctor were performed during the baseline period. The interviews addressed the subjects' current diet, eating habits, inclusion criteria, and motivational matters. The subjects were eligible for inclusion if they fulfilled the following criteria: (1) no gastrointestinal, renal or hepatic disease; (2) normal blood glucose and lipid concentrations; (3) BMI between 20 and $29 \mathrm{~kg} / \mathrm{m}^{2}$; (4) no alcoholism; (5) not a current smoker; (6) no use of supplemental vitamins and/or minerals for at least 6 months before the baseline of the study; (7) no food allergy. Pregnant and lactating women were excluded. Altogether, thirty-seven subjects were eligible. The study was carried out in accordance with the instructions of the Declaration of Helsinki. Informed consent was obtained from each participant. The study was approved by the Ethical Committee of the Faculty of Medicine, University of Oulu.

\section{Study design}

This crossover study consisted of a 2-week baseline period and two 5-week study periods (low-folate diet and highfolate diet) with a 3-week washout period in between. During the baseline and washout periods, the subjects consumed their habitual diets, i.e. they were instructed to continue their regular home diets. At the end of the baseline, the subjects were randomised into two groups. Half of the subjects $(n 18)$ were first on a low-folate diet followed by a high-folate diet, whereas the other half ( $n$ 19) had the order of the two diets reversed.

\section{Diets}

Both diets were designed on the basis of the regular hospital meals (a 5-week menu), and they contained conventional foods and beverages. A basic day's menu included a breakfast, lunch, afternoon snack, dinner, and evening snack. The breakfast consisted of bread and/or breakfast cereals and low-fat milk products. For lunch and dinner, warm dishes of meat, poultry, or fish with potatoes, pasta, or rice were served. The lunch and dinner included a dessert. The afternoon snack contained a low-fat cake with coffee or tea, and the evening snack consisted of bread and cheese. The foods were prepared, packaged, and delivered to the subjects by the hospital kitchen. On working days, the lunches and dinners were served at the hospital cafeteria. The participants could also take the packaged dinner meals home. On weekends, the subjects were able to eat the lunches and dinners at the hospital cafeteria or take the packaged weekend meals home on Friday. Other foodstuffs, including bread, milk, and fruit, were delivered to the subjects twice weekly.

Both study diets were energy-balanced and low in dietary cholesterol $(<200 \mathrm{mg} / \mathrm{d})$ and saturated fat (approximately $10 \%$ of total energy intake). During both diets, the quantity and quality of dietary fat were controlled by using low-fat meat and dairy products, low-fat cooking methods, and vegetable oil and margarine. The low-folate diet contained one serving of both fresh vegetables and fresh fruit or fruit juice/d. The dietary intake of folate during the low-folate diet was calculated to be approximately $200 \mu \mathrm{g} / \mathrm{d}$.

During the high-folate diet, the intake of dietary folate was increased by increasing the consumption of fresh vegetables, citrus fruits, and berries. During the intervention, there were no folate-fortified foods available in Finland. At the breakfast of the high-folate diet, the subjects ate approximately $30 \mathrm{~g}$ of fresh paprika and a piece of fruit, for example, orange or kiwi, or $125 \mathrm{ml}$ of juice in addition to whole-grain bread, breakfast cereals, and low-fat milk. The lunch included approximately $100-150 \mathrm{~g}$ of salad from carrots, cauliflower, cabbage, or other fresh vegetables, and approximately $100 \mathrm{~g}$ of steamed vegetables, for example, broccoli, peas, carrots, or cauliflower, in addition to the basic diet. The vegetables were steamed in a combined steam-convection oven. Fresh strawberries, blackcurrants, or raspberries were served as a dessert. At the dinner, approximately the same amounts of fresh and steamed vegetables were consumed. The dessert of the dinner consisted of either fresh berries or a piece of fruit. At both lunch and dinner, $100 \mathrm{ml}$ of orange juice was consumed. In the evening, the subjects ate $30 \mathrm{~g}$ of red paprika and $125 \mathrm{ml}$ of orange or pineapple juice together with whole-grain bread and low-fat cheese. The high intake of vegetables, citrus fruit, and berries was designed to result in an average of $600 \mu \mathrm{g}$ folate/d.

The same experienced nutritionist (M-LS) interviewed all the participants concerning their eating and exercise habits and determined an identical energy intake level for each participant. During the intervention, the participants weighed themselves daily before lunch, and their dietary energy intake was adjusted to maintain their body weight unchanged during the study. The nutritionist surveyed the study lunches daily and was able to assess the subjects' compliance. In addition, the subjects submitted a written report of any deviation in their diet. According to the subjects' reports, they followed their study diets without major exceptions. Alcohol consumption was determined at the baseline by interviewing the subjects, who were advised to restrict their use of alcohol to less than four drinks/ week during the study. The amount of alcohol consumed was negligible, and alcohol was therefore not included in the calculations of diets.

\section{Laboratory methods}

At the baseline, overnight fasting blood samples were drawn for the clinical chemistry tests and for the measurement of plasma tHcy, serum and erythrocyte (RBC) folate, and serum vitamin $B_{12}$, which were also measured at the 
end of both study periods. The concentrations of plasma tHcy and serum folate and vitamin $B_{12}$, but not RBC folate, were also determined at the end of the washout period.

The concentrations of serum and RBC folate and serum $\mathrm{B}_{12}$ were determined using the Quantaphase II $\mathrm{B}_{12}$ and Folate Radioassays (Bio-Rad Laboratories, Inc., 1996). For folate, the intra- and interassay $\mathrm{CV}$ were $5.6-8.6 \%$, depending on the folate concentration. For vitamin $\mathrm{B}_{12}$, the intra- and interassay $\mathrm{CV}$ were less than $3.3 \%$. For folates and vitamin $B_{12}$, the mean recoveries from analyses of three different quality assurance sera (Labquality Ltd, Finland) were 107 and $97 \%$, respectively. The plasma tHcy concentration was analysed by the immunofluorometric IMX method (Abbott Laboratories, IL) (Shipchandler \& Moore, 1995). The interassay $\mathrm{CV}$ was $3.2 \%$. Accuracy was ascertained by participating in a Nordic quality assurance system on plasma tHcy, in which the mean bias for seven sera was $-3.5 \%$ (Möller et al. 1997).

\section{Dietary analyses}

Diet records over $4 \mathrm{~d}$ were collected during the baseline diet period after the first visit to our laboratory, and their nutrient contents were calculated using the Nutrica software (Social Insurance Institution, Helsinki, Finland) based on the Finnish nutrient database. The dietary intake during the intervention periods was analysed (Agricultural Research Centre of Finland, Jokioinen, Finland) from identical food portions collected daily at a $7.5 \mathrm{MJ}$ energy intake level and pooled for each period. The nutrient analysis included total energy, total fat, carbohydrate, fibre, fatty acids, dietary cholesterol, $\mathrm{K}, \mathrm{Ca}, \mathrm{Fe}, \alpha$-carotene, $\beta$-carotene, ascorbic acid and $\alpha$-tocopherol. The analyses did not provide the contents of folate, vitamin $\mathrm{B}_{6}$, and vitamin $\mathrm{B}_{12}$, whose dietary intakes were calculated from the $35 \mathrm{~d}$ study menus using the Nutrica software.

\section{Statistical analyses}

The estimation of group size was based on a $15 \%$ decrease in the tHcy concentration after a 4-week daily supplementation with $400 \mu \mathrm{g}$ folic acid and vitamin $\mathrm{B}_{12}$ in healthy, young women (Brönstrup et al. 1998). On the basis of these data, thirty-three women were considered sufficient for detecting a change of $1.2 \mu \mathrm{mol} / \mathrm{l}$ in the plasma tHcy concentration with a power of $80 \%$ and an $\alpha$ of 0.05 .

The measurements of plasma tHcy and serum and RBC folate were not normally distributed, and non-parametric tests were therefore used in the statistical analyses of these parameters. Sign test (plasma tHcy, serum and RBC folate) and Student's $t$ test for paired samples (serum vitamin $\mathrm{B}_{12}$ ) were used to test the difference between the low- and high-folate diets. Spearman's correlation coefficient was used to determine the associations between the variables. The changes in serum and BRC folate, plasma tHcy, and serum vitamin $\mathrm{B}_{12}$ were calculated by subtracting the values of the low-folate diet from those of the high-folate diet for each individual subject. Because the changes of each variable were normally distributed, Student's $t$ test was used to assess the significance of the changes. The differences were considered significant at a $5 \%$ level. The SPSS software version 9.0 (SPSS Inc., Chicago, IL) was used in the statistical analyses. The values are expressed as means and standard deviations or means and $95 \% \mathrm{CI}$.

\section{Results}

The age, height and weight of the subjects ranged from 22 to 57 years (mean 43 (SD 10) years), from 1.55 to $1.72 \mathrm{~m}$ (mean $1.63 \mathrm{~m}$ ) and from 51.8 to $78.0 \mathrm{~kg}$ (mean $63.6 \mathrm{~kg}$ ), respectively. The subjects' BMI values remained unchanged during the study. Six subjects used oral contraceptives, and three subjects were on postmenopausal oestrogen and progestin supplementation. According to the nutrient calculations, the average dietary intake of folate of the women was 284 (SD 56) $\mu \mathrm{g} / \mathrm{d}$ at baseline and 221 (SD 24) and 596 (SD 66) $\mu \mathrm{g} / \mathrm{d}$ during the low- and highfolate diet periods, respectively (Table 1). The dietary intake of vitamin $\mathrm{B}_{6}$ was higher $(P<0.001)$ during the high-folate diet than on the low-folate diet (Table 1). In contrast, the dietary intake of vitamin $\mathrm{B}_{12}$ was lower $(P<0.001)$ during the high-folate diet than on the lowfolate diet (Table 1).

At baseline, the serum folate concentrations ranged from 6.0 to $24.0 \mathrm{nmol} / \mathrm{l}$ (mean 11.0 (SD 3.7 ) nmol/l; Table 2). The serum and RBC folate concentrations correlated positively at baseline $(r 0.56 ; P<0.001)$. The subjects' age correlated with both the initial serum folate $(r 0.36$; $P=0.028)$ and the RBC folate $(r 0.50 ; P=0.002)$ concentrations. The average serum folate concentration was 11.0 (SD 3.0) nmol/l (range 6.1-18.0 nmol/l) at the end of the low-folate diet, and increased by $78(95 \%$ CI 62, 94) \% in response to the high-folate diet $(P<0 \cdot 001$; Table 2$)$.

The subjects' basal RBC folate concentration ranged from 235 to $879 \mathrm{nmol} / \mathrm{l}$. The average $\mathrm{RBC}$ folate concentration was 412 (SD 120) $\mathrm{nmol} / \mathrm{l}$ at the end of the lowfolate diet and increased by $14(95 \%$ CI 8,20$) \%$ in response to the high-folate diet $(P<0 \cdot 001 ;$ Table 2$)$. The serum concentration of vitamin $\mathrm{B}_{12}$ tended to be higher at the end of the low-folate diet than the high-folate diet, but the difference was not statistically significant $(P=0 \cdot 079$; Table 2).

The basal plasma tHcy concentrations of the subjects ranged from 6.0 to $13.3 \mu \mathrm{mol} / \mathrm{l}$ (mean 8.1 (SD 1.9) $\mu \mathrm{mol} /$ 1; Table 2). At baseline, the plasma tHcy concentration correlated negatively with the serum vitamin $\mathrm{B}_{12}$ concentration $(r-0.36 ; \quad P=0.03)$ and the serum folate concentration $(r-0.46 ; P=0.004)$, but not with the RBC folate concentration $(r-0.25 ; P=0.13)$. The mean plasma tHcy concentration was 8.0 (SD 1.4) $\mu \mathrm{mol} / 1$ at the end of the low-folate diet and decreased by $13(95 \% \mathrm{CI}$ $9,18) \%$ during the high-folate diet $(P<0.001$; Table 2$)$. The absolute change of the plasma tHcy concentration between the study diets correlated positively with the plasma tHcy concentration of the low-folate diet $(r 0.50$; $P=0.002)$ and negatively with the serum folate $(r-0.34$; $P=0.042)$ and RBC folate $(r-0.39 ; P=0.018)$ concentrations of the low-folate diet. The change of plasma tHcy concentration correlated with the change in the RBC folate concentration $(r 0.42 ; P=0.011)$, but not with 
Table 1. Average daily nutrient intake of the participating women $(n 37)$ during the study diets $†$

(Mean values and standard deviations for calculated intakes, and mean values for analysed intakes)

\begin{tabular}{|c|c|c|c|c|c|c|}
\hline & \multicolumn{2}{|c|}{ Baseline } & \multicolumn{2}{|c|}{ Low-folate diet } & \multicolumn{2}{|c|}{ High-folate diet } \\
\hline & Mean & SD & Mean & SD & Mean & SD \\
\hline Carbohydrate (g) & 197 & 44 & 192 & & 220 & \\
\hline Protein $(\mathrm{g})$ & 73 & 16 & 84 & & 87 & \\
\hline Total fat (g) & 70 & 25 & 56 & & 59 & \\
\hline Saturated fat $(\mathrm{g})$ & 28 & 10 & 20 & & 19 & \\
\hline Monounsaturated fat $(\mathrm{g})$ & 26 & 10 & 23 & & 21 & \\
\hline Polyunsaturated fat $(\mathrm{g})$ & 11 & 4 & 13 & & 19 & \\
\hline Dietary fibre $(\mathrm{g})$ & 21 & 6 & 25 & & 40 & \\
\hline $\mathrm{Ca}(\mathrm{mg})$ & 1086 & 326 & 1210 & & 1280 & \\
\hline $\mathrm{K}(\mathrm{mg})$ & 3538 & 640 & 4200 & & 5720 & \\
\hline $\mathrm{Fe}(\mathrm{mg})$ & 11 & 3 & $10 \cdot 0$ & & 13.5 & \\
\hline Carotenoids (mg) & 3.4 & $2 \cdot 3$ & 4.6 & & 18 & \\
\hline Vitamin C (mg) & 128 & 60 & 147 & & 430 & \\
\hline Vitamin $\mathrm{E}(\mathrm{mg})$ & 10 & 4 & 8 & & 17 & \\
\hline Folate $(\mu \mathrm{g}) \ddagger$ & 284 & 56 & 221 & 24 & $596^{*}$ & 66 \\
\hline Vitamin $\mathrm{B}_{6}(\mathrm{mg}) \ddagger$ & 1.8 & 0.4 & 1.6 & 0.3 & $2 \cdot 7^{\star}$ & 0.3 \\
\hline Vitamin $B_{12}(\mu \mathrm{g}) \ddagger$ & $5 \cdot 7$ & $2 \cdot 3$ & $7 \cdot 1$ & $3 \cdot 6$ & $6 \cdot 4^{*}$ & 3.5 \\
\hline
\end{tabular}

* Mean values were significantly different from those of the low-folate diet $(P<0.001)$ (Sign test).

$\dagger$ The intakes at baseline were calculated from the $4 \mathrm{~d}$ food records and the intakes on the low- and high-vegetable diets were analysed from identical food portions.

¥ The dietary intakes of folate and the vitamins $B_{6}$ and $B_{12}$ in the low- and high-folate diets were calculated from the study menus.

Table 2. Concentrations of serum and erythrocyte folate, serum vitamin $B_{12}$ and plasma total homocysteine in the participating women ( $n$ 37) during the study§

(Mean values and standard deviations)

\begin{tabular}{|c|c|c|c|c|c|c|c|c|}
\hline & \multicolumn{2}{|c|}{ Baseline } & \multicolumn{2}{|c|}{ Low-folate diet } & \multicolumn{2}{|c|}{ Washout } & \multicolumn{2}{|c|}{ High-folate diet } \\
\hline & Mean & SD & Mean & SD & Mean & SD & Mean & SD \\
\hline Serum folate $(\mathrm{nmol} / \mathrm{l})$ & $11 \cdot 0$ & 3.7 & 11.0 & 3.0 & $13 \cdot 3^{*}$ & 5.5 & $19 \cdot 3+$ & $6 \cdot 4$ \\
\hline Erythrocyte folate $(\mathrm{nmol} / \mathrm{l})$ & 389 & 122 & 412 & 120 & \multicolumn{2}{|c|}{ ND } & $464 \dagger$ & 138 \\
\hline Serum vitamin $\mathrm{B}_{12}(\mathrm{nmol} / \mathrm{l})$ & 328 & 87 & 366 & 98 & $352 \ddagger$ & 97 & 351 & 104 \\
\hline Plasma total homocysteine $(\mu \mathrm{mol} / \mathrm{l})$ & $8 \cdot 1$ & 1.9 & 8.0 & 1.4 & $7 \cdot 8$ & 1.5 & $6.9+$ & 1.5 \\
\hline
\end{tabular}

ND, not determined.

${ }^{*}$ Mean value was significantly different from that at baseline $(P<0.05)$ (Sign test).

† Mean values were significantly different from those of the low-folate diet $(P<0.001)$ (Sign test)

$\ddagger$ Mean value was significantly different from that at baseline $(P<0.001)$ (Sign test).

$\S$ For details of diets and procedures, see Table 1 and p. 296.

the change in the serum folate concentration $(r 0.05$; $P=0.755)$.

\section{Discussion}

In the present study, the average plasma tHcy concentration of healthy women decreased by $13 \%$ in response to the diet high in vegetables, berries, and fruit, which was high in natural folate. Also, the high-folate diet markedly increased the serum and RBC folate concentrations. The majority of previous intervention studies have been conducted using synthetic folic acid, which has been found to increase serum and RBC folate and to decrease plasma tHcy (Ward et al. 1997; Brönstrup et al. 1998; Brouwer et al. 1999a). There are only a few previous studies that have assessed the effects of dietary modifications and a high dietary intake of folate on the plasma tHcy concentration (Brouwer et al. 1999b; Appel et al. 2000; Riddell et al. 2000). The $13 \%$ decrease $(1 \cdot 1 \mu \mathrm{mol} / \mathrm{l})$ in the plasma tHcy concentration in the present study compares well with the previous findings. Brouwer et al. (1999b) reported a $1.5 \mu \mathrm{mol} / \mathrm{l}$ (14\%) decrease in plasma tHcy in response to a high dietary intake of folate, whereas Riddell et al. (2000) noticed a $9 \%$ reduction in plasma tHcy in their dietary folate group. In contrast, Appel et al. (2000) reported that plasma tHcy decreased by only $3.6 \%(0.34 \mu \mathrm{mol} / \mathrm{l})$ in their study group, which consumed a diet high in vegetables and low-fat dairy products.

The amounts of dietary folate have been somewhat different in the various studies. The average intake of $600 \mu \mathrm{g}$ dietary folate/d in the present study is compatible 
with the previous study (Brouwer et al. 1999b), in which the intake of dietary folate from food was $560 \mu \mathrm{g} / \mathrm{d}$. It is notable that the average dietary intake of $600 \mu \mathrm{g}$ natural folate/d produced a remarkable relative increase $(78 \%)$ in the mean serum folate concentration in our study. Good compliance with the high-folate diet may have attributed to the extensive increase of serum folate. Also, compared with the previous studies (Brouwer et al. 1999b; Appel et al. 2000; Riddell et al. 2000), the average initial serum folate concentration of our study subjects was quite low, probably because their diets contained no synthetic folic acid, i.e. vitamin supplements or fortified foods, before the study. The relatively low serum folate concentration at baseline and at the end of the low-folate diet may partly explain the extensive increase in the serum folate concentration in response to the high-folate diet. Interestingly, the change in the serum folate concentration between the low- and high-folate diets did not correlate with the change in the plasma tHcy concentration. However, the change in the RBC folate concentration correlated with the change in the plasma tHcy concentration, which supports the role of folate in reducing the plasma tHcy concentration in our study.

In most studies, serum or plasma folate concentrations are used as indicators of folate status and the dietary intake of folate (Herbert, 1987). Even though we had a relatively short washout period in our intervention, we also determined the RBC folate concentration, which is considered a better indicator of long-term folate intake and whole-body storage than the serum or plasma folate concentration (Herbert, 1987). Two previous studies (Cuskelly et al. 1996; Riddell et al. 2000) reported dietary folate to be relatively ineffective in increasing the RBC folate concentration. In contrast, we noticed a significant $14 \%$ increase in the RBC folate concentration in response to a diet high in natural folate. Also, Brouwer et al. $(1999 b)$ reported a similar $17 \%$ increase in the $\mathrm{RBC}$ folate concentration in their intervention with natural folate.
In addition to folate, the vitamins $\mathrm{B}_{6}$ and $\mathrm{B}_{12}$ are known to be important regulators of plasma tHcy (Mason \& Miller, 1992). In the present study, both diets provided the subjects with at least the recommended intakes of vitamins $\mathrm{B}_{6}$ and $B_{12}$. There were no major changes in the serum concentrations of vitamin $\mathrm{B}_{12}$ during the study, which does not support the role of vitamin $\mathrm{B}_{12}$ in reducing the plasma tHcy concentration in our study. However, the dietary intake of vitamin $\mathrm{B}_{6}$ was about $1 \mathrm{mg}$ higher during the high-folate diet than the low-folate diet, which might have influenced the plasma tHcy concentration. In addition to the group B vitamins, other dietary factors may affect the plasma tHcy concentration. A reduced plasma tHcy concentration has been achieved with a diet high in vegetables with a relatively low folate intake $(228 \mu \mathrm{g} / \mathrm{d}$; Broekmans et al. 2000). This finding suggests that other components than folate in vegetables and fruit may affect the plasma tHcy concentration. Furthermore, these findings emphasise the role of a whole diet with a high intake of vegetables, fruit, and berries in reducing plasma homocysteine levels.

In Finland, vegetables, berries, fruit, and whole grains are the major contributors to the dietary folate intake, which is $303 \mu \mathrm{g}$ and $240 \mu \mathrm{g} / \mathrm{d}$ for men and women, respectively (The 1997 dietary survey of Finnish adults, The National Public Health Institute, 1998). The current Nordic recommendation for the dietary intake of folate is $300 \mu \mathrm{g} / \mathrm{d}$ for adults (Nordic Nutrition Recommendations, 1996). At the baseline of the present study, the average dietary folate intake $(284 \mu \mathrm{g} / \mathrm{d})$ of the subjects was only slightly below the recommended level. Compared with the recommendation, our low-folate diet was not particularly low in dietary folate. In fact, the low-folate diet was planned to provide the subjects with the currently recommended intakes of other nutrients, such as group B vitamins, vitamin $\mathrm{C}, \mathrm{Ca}$, and $\mathrm{Fe}$, rather than to be a depletion diet. On the whole, the nutrient intakes during the low-folate diet were compatible with the intakes at baseline and also with the current average dietary intake in Finland (The 1997 dietary survey of Finnish adults, The National Public Health Institute, 1998).

Table 3. Concentrations of serum and erythrocyte folate, serum vitamin $\mathrm{B}_{12}$ and plasma total homocysteine of individual arms of the cross-over study $†$

(Mean values and standard deviations)

\begin{tabular}{|c|c|c|c|c|c|c|c|c|}
\hline & \multicolumn{2}{|c|}{$\begin{array}{l}\text { Serum folate } \\
(\mathrm{nmol} / \mathrm{l})\end{array}$} & \multicolumn{2}{|c|}{$\begin{array}{c}\text { Erythrocyte } \\
\text { folate }(\mathrm{nmol} / \mathrm{l})\end{array}$} & \multicolumn{2}{|c|}{$\begin{array}{l}\text { Serum vitamin } \\
\mathrm{B}_{12}(\mathrm{nmol} / \mathrm{l})\end{array}$} & \multicolumn{2}{|c|}{$\begin{array}{c}\text { Plasma total } \\
\text { homocysteine } \\
(\mu \mathrm{mol} / \mathrm{l})\end{array}$} \\
\hline & Mean & $\mathrm{SD}$ & Mean & SD & Mean & SD & Mean & SD \\
\hline \multicolumn{9}{|c|}{ Women who consumed the low-folate diet first ( $n$ 18) } \\
\hline Baseline & $10 \cdot 8$ & $4 \cdot 1$ & 380 & 138 & 352 & 99 & $7 \cdot 6$ & 1.4 \\
\hline Low-folate diet & $10 \cdot 1$ & $2 \cdot 4$ & 372 & 120 & 375 & 113 & $8 \cdot 1$ & $1 \cdot 3$ \\
\hline Washout & $12 \cdot 1$ & $5 \cdot 3$ & \multicolumn{2}{|c|}{ ND } & 379 & 108 & $6 \cdot 8$ & 1.6 \\
\hline High-folate diet & $21 \cdot 0$ & $6 \cdot 4$ & 473 & 134 & 396 & 118 & $6 \cdot 4$ & 1.0 \\
\hline \multicolumn{9}{|c|}{ Women who consumed the high-folate diet first ( $n$ 19) } \\
\hline Baseline & $11 \cdot 0$ & $3 \cdot 3$ & 398 & 108 & 310 & 66 & $8 \cdot 7$ & $2 \cdot 2$ \\
\hline High-folate diet & $17 \cdot 7$ & $6 \cdot 1$ & 455 & 145 & 307 & 68 & $7 \cdot 4$ & $1 \cdot 7$ \\
\hline Washout & $14 \cdot 4^{*}$ & $5 \cdot 7$ & \multicolumn{2}{|c|}{ ND } & 326 & 79 & $7 \cdot 8$ & 1.5 \\
\hline Low-folate diet & 11.9 & $3 \cdot 2$ & 450 & 110 & 358 & 83 & $7 \cdot 9$ & 1.5 \\
\hline
\end{tabular}

ND, not determined.

* Mean value was significantly different from that at baseline $(P<0.05)$ (Sign test)

†For details of diets and procedures, see Table 1 and p. 296. 
In the present crossover study, the washout period turned out to be relatively short (Brouwer et al. 1999a), and some (Table 3) carry-over effect on serum folate could be observed. The serum folate concentration was somewhat higher at the end of the washout period $(13.3 \mathrm{nmol} / \mathrm{l})$ than at the baseline $(11.0 \mathrm{nmol} / 1$; Table 2$)$. Therefore, the carry-over effect may be a potential confounding factor, but this would dilute the actual change that could have been obtained in our study. Indeed, the changes in the serum folate and plasma tHcy concentrations could have been even larger if the washout period had been longer. Also, it is notable that the plasma tHcy concentrations at the baseline and at the end of the washout period were equal $(8 \cdot 1 \mu \mathrm{mol} / \mathrm{l} v .7 \cdot 8 \mu \mathrm{mol} / \mathrm{l}$; Table 2$)$.

Some observational studies (Stampfer et al. 1992; Arnesen et al. 1995; Perry et al. 1995; Nygård et al. 1997; Wald et al. 1998; Bostom et al. 1999a, b) have shown that homocysteine is an independent risk factor for cardiovascular diseases. However, several cohort studies (Alfthan et al. 1994; Verhoef et al. 1994; Chasan-Taber et al. 1996; Evans et al. 1997; Folsom et al. 1998) fail to show a significant association between homocysteine and the risk of myocardial infarction, $\mathrm{CHD}$, or stroke. Until the results of intervention trials on homocysteine-lowering vitamin therapy become available, preventive action with vitamin B supplementation in the general population or in patients with cardiovascular disease is not justifiable (Nygård et al. 1999). In the present study, we used a whole-diet approach to show that the serum and RBC folate concentrations can be markedly increased and the plasma total homocysteine concentration decreased by a diet high in vegetables, berries, and fruit, which is high in natural folate. Compared with supplemental folic acid intake, the dietary modification has the additional benefit of increasing the intake of other important nutrients as well.

\section{Acknowledgements}

The authors thank Saija Kortetjärvi, Liisa Mannermaa, Sirpa Rannikko, and Eila Saarikoski for their skilful laboratory assistance during the study. This work was supported in part by the Research Council for Health of the Academy of Finland and the Finnish Foundation for Cardiovascular Research.

\section{References}

Alfthan G, Pekkanen J, Jauhiainen M, Pitkäniemi J, Karvonen M, Tuomilehto J, Salonen JT \& Ehnholm C (1994) Relation of serum homocysteine and lipoprotein(a) concentrations to atherosclerotic disease in a prospective Finnish population based study. Atherosclerosis 106, 9-19.

Appel LJ, Miller ER III, Jee SH, Stolzenberg-Solomon R, Lin PH, Erlinger T, Nadeau MR \& Selhub J (2000) Effect of dietary patterns on serum homocysteine: results of a randomized, controlled feeding study. Circulation 102, 852-857.

Arnesen E, Refsum H, Bonaa KH, Ueland PM, Forde OH \& Nordrehaug JE (1995) Serum total homocysteine and coronary heart disease. International Journal of Epidemiology 24, 704-709.
Bostom AG, Rosenberg IH, Silbershatz H, Jacques PF, Selhub J, D'Agostino RB, Wilson PW \& Wolf PA (1999a) Nonfasting plasma total homocysteine levels and stroke incidence in elderly persons: the Framingham Study. Annals of Internal Medicine 131, 352-355.

Bostom AG, Silbershatz H, Rosenberg IH, Selhub J, D'Agostino RB, Wolf PA, Jacques PF \& Wilson PW (1999b) Nonfasting plasma total homocysteine levels and all-cause and cardiovascular disease mortality in elderly Framingham men and women. Archives of Internal Medicine 159, 1077-1080.

Broekmans WM, Klopping-Ketelaars IA, Schuurman CR, Verhagen H, van den Berg H, Kok FJ \& van Poppel G (2000) Fruits and vegetables increase plasma carotenoids and vitamins and decrease homocysteine in humans. Journal of Nutrition 130, 1578-1583.

Brönstrup A, Hages M, Prinz-Langenohl R \& Pietrzik K (1998) Effects of folic acid and combinations of folic acid and vitamin B-12 on plasma homocysteine concentrations in healthy, young women. American Journal of Clinical Nutrition 68, 1104-1110.

Brouwer IA, van Dusseldorp M, Thomas CM, Duran M, Hautvast JG, Eskes TK \& Steegers-Theunissen RP (1999a) Low-dose folic acid supplementation decreases plasma homocysteine concentrations: a randomized trial. American Journal of Clinical Nutrition 69, 99-104.

Brouwer IA, van Dusseldorp M, West CE, Meyboom S, Thomas CM, Duran M, het Hof KH, Eskes TK, Hautvast JG \& Steegers-Theunissen RP (1999b) Dietary folate from vegetables and citrus fruit decreases plasma homocysteine concentrations in humans in a dietary controlled trial. Journal of Nutrition 129, 1135-1139.

Campbell NR (1996) How safe are folic acid supplements? Archives of Internal Medicine 156, 1638-1644.

Centers for Disease Control (1996) Nordic Nutrition Recommendations, Editorial. Scandinavian Journal of Nutrition 40, $161-165$.

Chasan-Taber L, Selhub J, Rosenberg IH, Malinow MR, Terry P, Tishler PV, Willett W, Hennekens CH \& Stampfer MJ (1996) A prospective study of folate and vitamin B6 and risk of myocardial infarction in US physicians. Journal of the American College of Nutrition 15, 136-143.

Cuskelly GJ, McNulty H \& Scott JM (1996) Effect of increasing dietary folate on red-cell folate: implications for prevention of neural tube defects. Lancet 347, 657-659.

Evans RW, Shaten BJ, Hempel JD, Cutler JA \& Kuller LH (1997) Homocyst(e)ine and risk of cardiovascular disease in the Multiple Risk Factor Intervention Trial. Arteriosclerosis, Thrombosis, and Vascular Biology 17, 1947-1953.

Folsom AR, Nieto FJ, McGovern PG, Tsai MY, Malinow MR, Eckfeldt JH, Hess DL \& Davis CE (1998) Prospective study of coronary heart disease incidence in relation to fasting total homocysteine, related genetic polymorphisms, and B vitamins: the Atherosclerosis Risk in Communities (ARIC) study. Circulation 98, 204-210.

Hankey GJ \& Eikelboom JW (1999) Homocysteine and vascular disease. Lancet 354, 407-413.

Herbert V (1987) Recommended dietary intakes (RDI) of folate in humans. American Journal of Clinical Nutrition 45, 661-670.

Jacques PF, Selhub J, Bostom AG, Wilson PW \& Rosenberg IH (1999) The effect of folic acid fortification on plasma folate and total homocysteine concentrations. New England Journal of Medicine 340, 1449-1454.

McCully KS (1996) Homocysteine and vascular disease. Nature Medicine 2, 386-389.

Mason JB \& Miller JW (1992) The effects of vitamins B12, B6, and folate on blood homocysteine levels. Annals of the New York Academy of Sciences 669, 197-203.

Möller J, Christensen L \& Rasmussen K (1997) An external 
quality assessment study on the analysis of methylmalonic acid and total homocysteine in plasma. Scandinavian Journal of Clinical and Laboratory Investigation 57, 613-619.

National Public Health Institute (1998) The 1997 dietary survey of Finnish adults, Publication of the National Public Health Institute, B 8/1998. Hakapaino, Helsinki, Finland: National Public Health Institute, Department of Nutrition.

Nygård O, Nordrehaug JE, Refsum H, Ueland PM, Farstad M \& Vollset SE (1997) Plasma homocysteine levels and mortality in patients with coronary artery disease. New England Journal of Medicine 337, 230-236.

Nygård O, Vollset SE, Refsum H, Brattstrom L \& Ueland PM (1999) Total homocysteine and cardiovascular disease. Journal of Internal Medicine 246, 425-454.

Omenn GS, Beresford SA \& Motulsky AG (1998) Preventing coronary heart disease: B vitamins and homocysteine. Circulation 97, 421-424.

Perry IJ, Refsum H, Morris RW, Ebrahim SB, Ueland PM \& Shaper AG (1995) Prospective study of serum total homocysteine concentration and risk of stroke in middle-aged British men. Lancet 346, 1395-1398.

Recommendations for the use of folic acid to reduce the number of cases of spina bifida and other neural tube defects (1992) MMWR Morbidity \& Mortality Weekly Report 41, 1-7.
Riddell LJ, Chisholm A, Williams S \& Mann JI (2000) Dietary strategies for lowering homocysteine concentrations. American Journal of Clinical Nutrition 71, 1448-1454.

Shipchandler MT \& Moore EG (1995) Rapid, fully automated measurement of plasma homocyst(e)ine with the Abbott IMx analyzer. Clinical Chemistry 41, 991-994.

Stampfer MJ, Malinow MR, Willett WC, Newcomer LM, Upson B, Ullmann D, Tishler PV \& Hennekens CH (1992) A prospective study of plasma homocyst(e)ine and risk of myocardial infarction in US physicians. Journal of the American Medical Association 268, 877-881.

Verhoef P, Hennekens CH, Malinow MR, Kok FJ, Willett WC \& Stampfer MJ (1994) A prospective study of plasma homocyst(e)ine and risk of ischemic stroke. Stroke 25, $1924-1930$.

Wald NJ, Watt HC, Law MR, Weir DG, McPartlin J \& Scott JM (1998) Homocysteine and ischemic heart disease: results of a prospective study with implications regarding prevention. Archives of Internal Medicine 158, 862-867.

Ward M, McNulty H, McPartlin J, Strain JJ, Weir DG \& Scott JM (1997) Plasma homocysteine, a risk factor for cardiovascular disease, is lowered by physiological doses of folic acid. Quarterly Journal of Medicine 90, 519-524. 